\title{
SOME NOTES ON THE EARLY STAGES, ESPECIALLY THE CHRYSALIS, OF A FEW AMERICAN SPHINGIDAE.
}

\author{
BY SAMUEL H. SCUDDER.
}

The subjoined descriptions are wholly from notes taken twenty or thirty years ago, and complement in part the larval descriptions given in B. P. Mann's paper in the second volume of Psyche.

\section{MACROSILA CAROLINA.}

Egg. Round, very light green, and perfectly smooth so far as can be seen with an ordinary lens. They are laid singly, and rarely more than one is found upon the same plant.

Caterpillar. (See Psyche, v. 2, p. 73-75, for description of the larva, drawn up at the same time.)

Chrysalis. Dark reddish brown with a slight dark olivaceous tint on the wings, the edges of the segments darker than the middle; spiracles and tongue black. The body is deeply hollowed at the metathorax on either side of the centre, somewhat constricted at the prothorax, and has a central depressed line and a pit on either side of it upon the front of the fifth and sixth abdominal segments. Metathorax and hind wings not very conspicuous, the former with a transverse backward directed ridge. The tongue is free except at its bulbous tip, shorter than in M. quinquemaculata, and slightly incurved on its downward trend; its extreme tip is placed at one-third the distance from the head to the tip of the body and halfway between the front of the head and the tip of the wings, while in $M$. quinquemaculata it is at half that distance. The hind legs reach the tip or nearly the tip of the wings which extend over four abdominal segments. Before the spiracles on the $5^{\text {th }}-7_{\text {th }}$ abdominal segments there is a slit five or six times as long as the spiracles, the posterior edge raised and lipped, and the top ridged above, the whole being black, and undoubtedly serving for the movement of the pupa in reaching again the surface of the ground; precisely the same thing occurs in other species of Macrosila. The head, thorax, and appendages are quite smooth, being only faintly wrinkled, except the tongue which is roughly wrinkled; the abdominal segments are profusely punctate anteriorly, punctate or rather pitted and wrinkled in the centre and, at least on the 4 th- 7 th segments, very minutely and delicately punctate posteriorly: the last two segments are very deeply erose; the cremaster obtusely conical, tranversely compressed, having two short points with their inner edges diverging, but their outer edges nearly parallel. Length $50 \mathrm{~mm}$.; breadth $\mathrm{I} 4 \mathrm{~mm}$.

Some caterpillars which went under ground about August 27 had not changed on September 5, but changed within eight days thereafter. They seldom bury themselves more than three or four inches, and make an underground cavern with sides of packed earth.

\section{SPHINX CINEREA.}

Chrysalis. Mahogany brown, edges o segments slightly darker. Body a little hollowed on either side of the metathorax and slightly constricted at the prothorax. Metathoracic wings visible down to the spiracle of third abdominal segment. Tongue detached, heavily wrinkled, carried along the front nearly parallel to the breast, the tip not 
bulbous and placed slightly more than a fourth way down the length of the body; the same structure before the spiracles as in Macrosila. Head, thorax, and appendages apparently smooth but faintly wrinkled; abdominal segments wrinkled and punctate evenly and not heavily, their posterior edges on $4^{\text {th-6th }}$ abdominal segments being minutely punctate. Cremaster large, conical, scarcely flattened and with two very minute points upon it. Length $46.5 \mathrm{~mm}$.; breadth $13 \mathrm{~mm}$.

Went under ground September 19.

\section{DOLBA HYLAEUS.}

Larval habits, etc. I placed a full grown larva found on Cape Cod early in September under a glass over a plant of sweet fern. The earth was clean, and he soon disappeared; but before doing so he bit off most of the leaves at their base, green and dried alike, and scattered them indiscriminately on the ground below, so that the earth was no longer to be seen, and until the leaves were removed I could not tell whether he was merely hidden beneath them or had gone under ground. No opening in the heap of leaves was discoverable. Ie had buried himself in the earth to the depth of about an inch in an oblique position, head uppermost.

The facces of this caterpillar are astonishingly large, forming an irregular cylindrical mass often I $2-14 \mathrm{~mm}$. long and $5 \mathrm{~mm}$. broad, of a pitchy black color, and looking like furnace slag, and bearing no such definite markings as are seen in Macrosila.

Parasites. While taking notes of the larvae, I was interrupted for a couple of hours, and was very much surprised on my return to find that one I had been describing just before was now covered with brown worms; no less than eight of them had fastened themselves by threads to the sides of their victim, some on the fifth and some on the eighth and ninth abdominal segments.

They were of a very light brown color, with a slight greenish tinge, having a dorsal row and on either side of it two other rows of small rounded elevations, one upon the anterior edge of each segment in each row; there was also a dark dorsal streak, and here and there dark reddish brown spots, especially upon the dorsal surface and the last three or four segments. The round thoracic spiracles were dark brown. The skin was glistening and very evenly and microscopically reticulate. The head had a faint greenish tinge, and upon each side were two black bent lines like a figure 5 upon its side, while the opposite extremity seems to have a little thicker integument than the rest of the body. Length $7 \mathrm{~mm}$.; breadth $2 \mathrm{~mm}$.

These creatures had wormed their way directly through the body wall of the caterpillar, leaving little brown pits in various parts of the body to mark their exit; but there seemed to be no wound as there certainly was no loss of any fluid; why is there none, and why do all the worms come out together? The caterpillar, on the under side of a leaf, remained motionless, looking very slender and flabby, and acting in a very dumpish nuanner.

As for the worms, they immediately began spinning their cocoons where they were, and when one was torn vio- 
lently away, the maker at once began a new cocoon, constructing one-half at a time, namely the half opposed to its own ventral surface, and when this was completed, it turned about and made the other half. When all were made, the cocoons were seen to lie in clusters, some horizontal but most perpendicular to the back of the caterpillar; they were made of a very fine glistening silk, and when completed were about $4.8 \mathrm{~mm}$. long by half as broad. It took one of them a little more than half an hour to completely envelope itself with silk, though much longer to complete the cocoon. These when finished much resemble the buds of Comptonia, being of a light chocolate brown color, roughly ribbed longitudinally about a dozen times, the ends smooth; they are loosely attached to the caterpillar. In escaping from their cocoon, the enclosed Hymenopteron bites off the top of the cocoon in an irregular manner. All that I had escaped me, and some came out at a time when others of the same lot still remained as larvae inside their cocoons.

The caterpillars may be found in nearly every stage throughout the month of August in eastern Massachusetts.

Chrysalis. Uniform shining mahogany in color, with the wings lacking polish.
The whole of the thorax and appendages are minutely wrinkled and all the abdominal segments are rather minutely punctured and also wrinkled; the wings cover the fourth abdominal segment; the tongue case is very short; the cremaster is long, slender, conical, straight, pointed, very rough at the base, smooth toward the tip. Length $3^{8}$ $\mathrm{mm}$.; breadth ro $\mathrm{mm}$.; length of tongue $4.25 \mathrm{~mm}$.

\section{HYLOICUS PLEBEIUS.}

Chrysalis. Black, the posterior margin of the 4 th-6th abdominal segments light brown and minutely striate transversely. Body shaped much as in Sphinx cinerea, with the same structure before the spiracles but less prominent; the shoulders prominent. Tongue short, free, regularly curved, rather thickened at the tip and one-third the length of the distance from the tip of the head to the tip of the wings. Metathoracic wings reaching the spiracles of the third abdominal segment. Antennae with a raised point in the centre of each joint. First joint of second pair of legs prominent. Head, thorax, and appendages wrinkled; abdominal segments coarsely wrinkled and deeply punctate. Cremaster like that of Sphinx cinerea, excepting that the tip is armed with a bifid prong which is down-curved. Length $44 \mathrm{~mm}$.; breadth $10.5 \mathrm{~mm}$.

One larva went into the ground on September 19, afterwards worked himself halfway and finally wholly out, and changed upon the surface September 25 . 

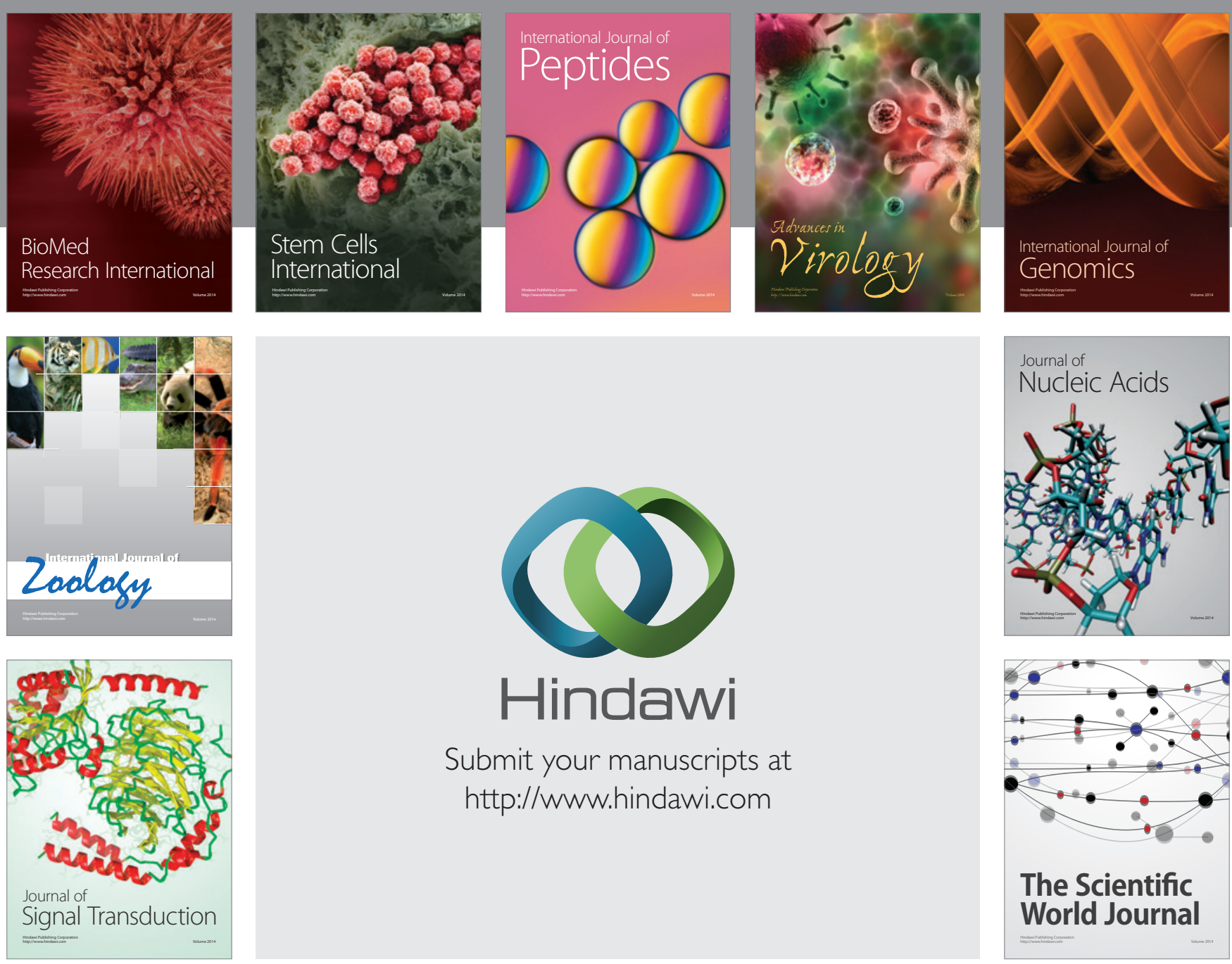

Submit your manuscripts at

http://www.hindawi.com
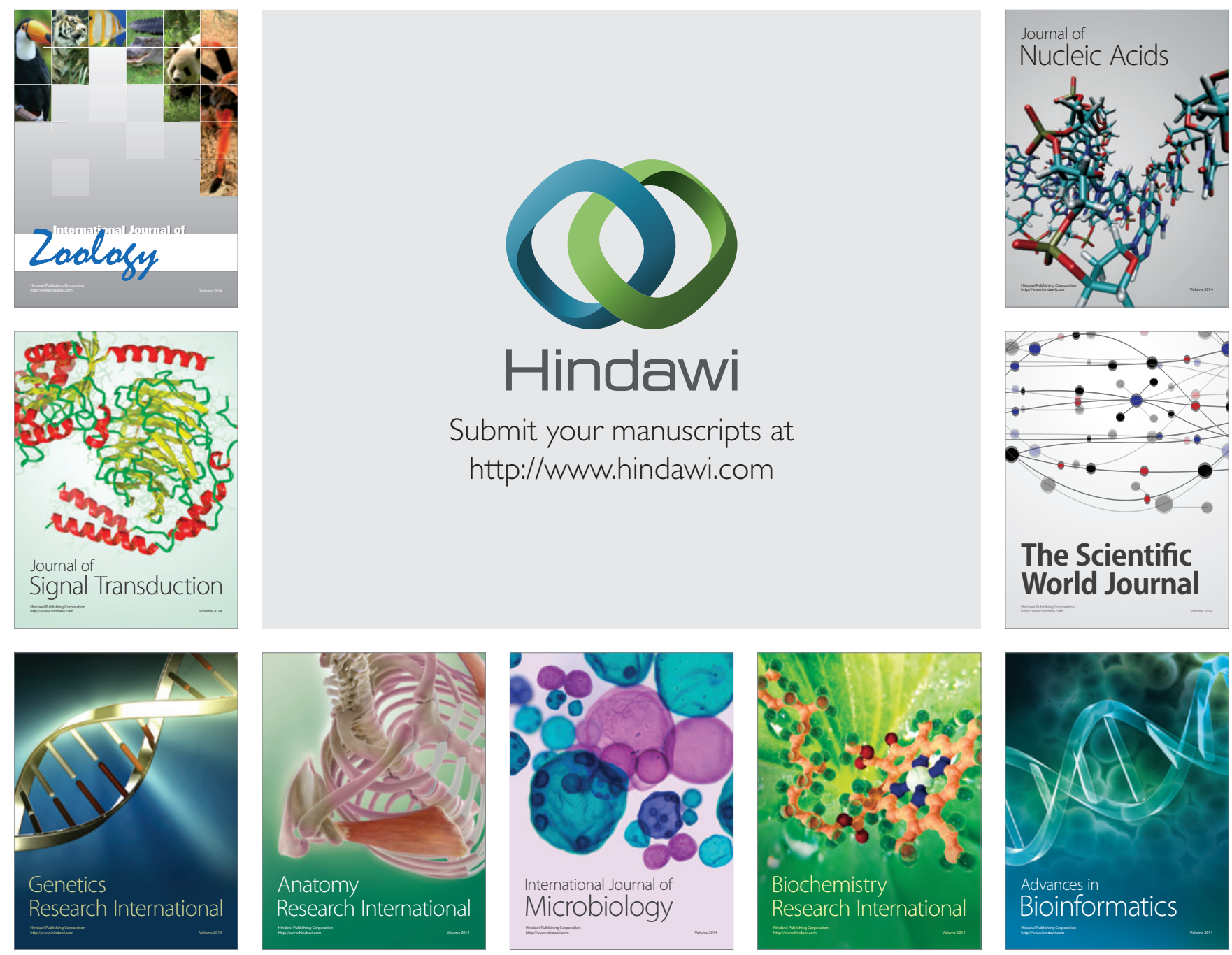

The Scientific World Journal
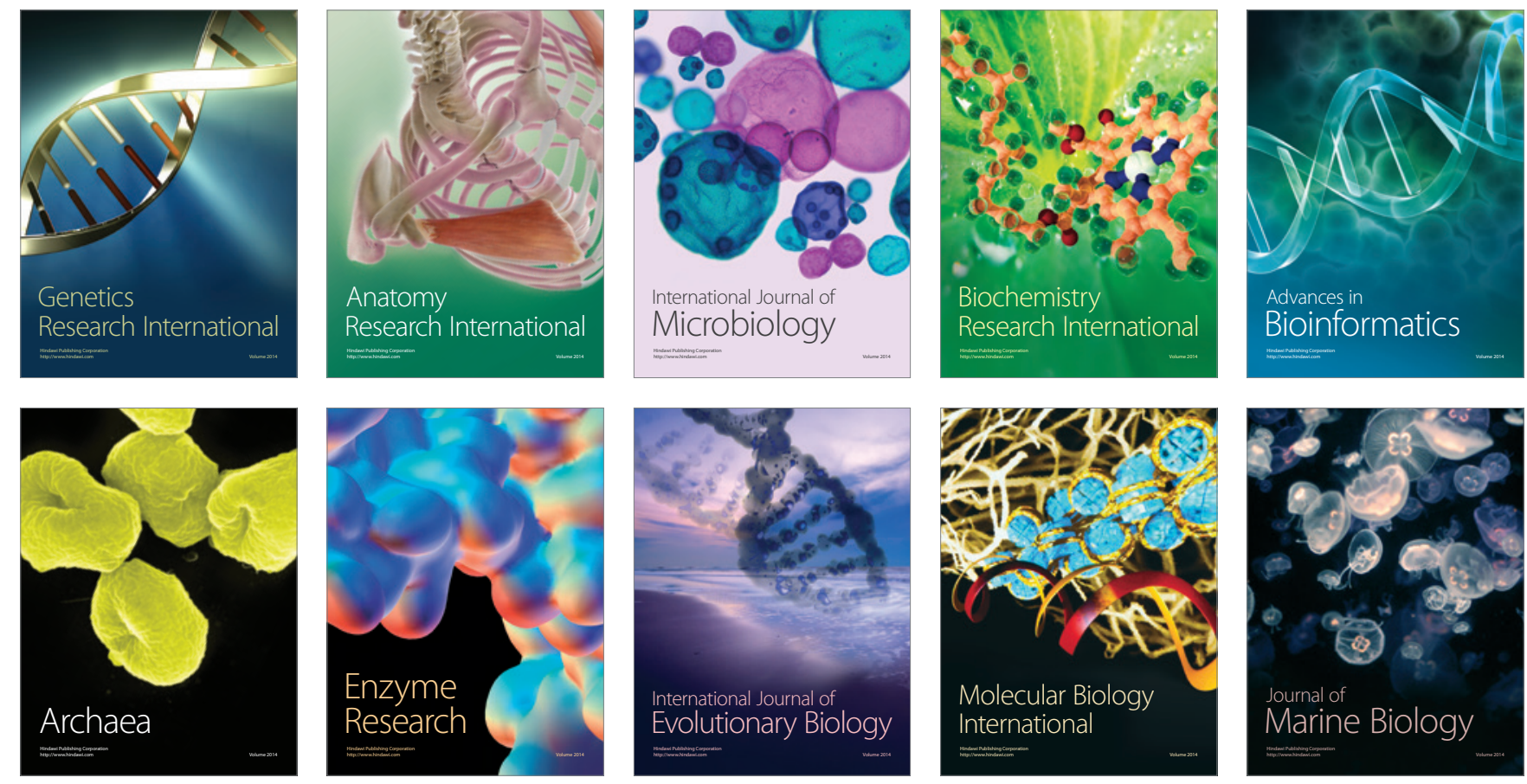